\title{
EDUCAÇÃO FÍSICA ESCOLAR: POSSIBILIDADES PARA OS CURSOS DE ENSINO MÉDIO INTEGRADO DO INSTITUTO FEDERAL DE EDUCAÇÃO, CIÊNCIA E TECNOLOGIA DE MATO GROSSO DO SUL - IFMS
}

\author{
Tiago Amaral Silva \\ E-mail: tiagoamaralueg@gmail.com \\ Instituto Federal de Educação, Ciência e Tecnologia do Paraná \\ DOI: 10.15628/rbept.2020.9660 \\ Artigo submetido em: Mar/2020 e aceito em Maio/2020
}

\begin{abstract}
RESUMO
O presente artigo foi desenvolvido a partir das experiências como professor nos Institutos Federais de Educação pelos quais passamos. O principal objetivo é discutir as possibilidades do ensino da Educação Física Escolar dentro dos currículos dos cursos de Ensino Médio Integrado no Instituto Federal de Mato Grosso do Sul (IFMS). A pesquisa é de natureza qualitativa e descritiva, sob a ótica dos Projetos Pedagógicos dos cursos desta modalidade na instituição pesquisada, além de produções científicas correlatas. Observamos que a Cultura Corporal de Movimento fundamenta a disciplina Educação Física nos currículos do IFMS, esta que ainda carece de uma estruturação epistemológica quando se trata da Educação Física voltada para cursos de Ensino Médio Integrado.
\end{abstract}

Palavras-Chave: Educação Física. Educação Profissional. Ensino Médio Integrado. Cultura Corporal de Movimento.

\section{PHYSICAL EDUCATION AT SCHOOLS: POSSIBILITIES FOR TECHNICAL VOCATIONAL HIGH SCHOOL COURSES OF FEDERAL INSTITUTE OF EDUCATION, SCIENCE AND TECHNOLOGY IN MATO GROSSO DO SUL - IFMS}

\begin{abstract}
This article was developed from experiences as a teacher in the federal institutes of education. The main objective is to discuss the possibilities of teaching physical education within the curriculum of technical vocational high school in the Federal Institute of Mato Grosso do Sul (IFMS). This research is qualitative and descriptive, from the perspective of the Pedagogical Projects of the courses of this modality in the researched institution, and it also contains related scientific productions. We observe that the Body Culture of Movement bases the physical education subject in the IFMS curricula, which still lacks an epistemological structure when it comes to physical education focused on technical vocational high school courses.
\end{abstract}

Keywords: Physical Education. Integrated High School. IFMS. Body Culture of Movement. 


\section{INTRODUÇÃO}

O Ensino Médio Integrado (EMI) é uma modalidade de curso ofertada pelas redes públicas e privadas do país, regulamentada a partir do Decreto 5.154 de 2004. (BRASIL, 2004). Tendo como eixos indissociáveis os elementos Trabalho, Ciência e Cultura, esta modalidade de curso vem crescendo enquanto uma alternativa ao Ensino Médio propedêutico que majoritariamente é o modelo vigente nas diversas redes de ensino do país no que diz respeito à última etapa da educação básica.

O currículo do EMI integra-se por meio de conhecimentos materializados nas diversas disciplinas do Ensino Médio convencional e com disciplinas vinculadas aos diversos eixos tecnológicos existentes no Catálogo Nacional de Cursos Técnicos do Ministério da Educação ${ }^{1}$. Neste sentido, como nos lembram Ferreira e Garcia (2012) o EMI é uma travessia para uma educação integral, politécnica, portanto de qualidade para todos, mesmo sendo um projeto ainda incipiente na educação brasileira.

As mais de 600 unidades dos Institutos Federais de Educação, Ciência e Tecnologia no Brasil, doravante (IFs), são instituições recentemente criadas a partir da reestruturação das antigas escolas técnicas e agrotécnicas federais, assim como, de alguns Centros Federais de Educação Tecnológica (CEFET) com a determinação da lei 11.892 de 2008. (BRASIL, 2008a). Juntamente com algumas escolas técnicas vinculadas às universidades federais, a Universidade Tecnológica Federal do Paraná, o Colégio Dom Pedro II e alguns colégios militares, formam a estrutura da Rede Federal de Educação, Ciência e Tecnologia no Brasil2.

No caso do Instituto Federal de Educação, Ciência e Tecnologia do Mato Grosso do Sul (IFMS), o qual atuamos como professor por 9 anos, sempre buscamos compreender quais as contribuições da Educação Física Escolar enquanto elemento estruturante dos currículos do EMI dos Institutos Federais de Educação, Ciência e Tecnologia.

Por esta razão desenvolvemos este texto, cujo objetivo é discutir as possibilidades do ensino da Educação Física Escolar dentro dos currículos dos cursos de EMI para os Institutos Federais de Educação, Ciência e Tecnologia.

Para compreendermos o que é o EMI, partimos de uma pesquisa feita por Ramos (2008), que explica-o a partir da análise do que vem a ser o elemento "integração". A compreensão da integração presente no EMI, perpassa por três direções específicas mas que se convergem em sua totalidade. Segundo Ramos (2008) o primeiro sentido da integração tem um caráter filosófico e diz respeito à formação humana, onde os eixos Trabalho, Ciência e Cultura são dimensões indissociáveis que explicam o caminho a ser trilhado para uma educação emancipadora dos sujeitos. Já o segundo sentido a autora entende que a integração é a forma de se relacionar a educação básica

\footnotetext{
${ }^{1}$ Brasil (2008b). Melhores informações do catálogo nacional dos cursos técnicos do MEC disponíveis em <http://portal.mec.gov.br/docman/novembro-2017-pdf/77451-cnct-3a-edicaopdf-1/file>

${ }^{2}$ Maiores detalhes sobre a Rede Federal de Educação, verificar: redefederal.mec.gov.br eplataformanilopecanha.org.

Vol. 2 (2020) 
com a educação profissional. Por fim, a integração também pode ser entendida como a relação entre parte e totalidade do currículo.

É a partir deste entendimento concebido por Ramos (2008) que nos referenciamos e buscamos compreender o EMI no IFMS. Ainda, na condição de docente da disciplina de Educação Física Escolar dos cursos de EMI nas áreas de Informática para Internet e Agricultura, nos aproximar das contribuições que esta unidade curricular tem para a escolarização dos diversos sujeitos que passam por esses cursos todos os anos nesta instituição. Muito nos intriga em saber o sentido e um significado para esta disciplina em currículo do EMI assim como muitos trabalhos já se aproximaram de compreender a Educação Física para o Ensino Médio convencional ou propedêutico.

Perante o contexto apresentado, o texto tem como objeto de investigação os principais elementos curriculares presentes na Educação Física Escolar do EMI no IFMS à luz de uma totalidade curricular (RAMOS, 2008). Diante disso, investigar a Educação Física para a construção de um EMI mais significativo, fomentará o debate sobre o entendimento desta modalidade de curso, como também contribuirá para uma ressignificação da Educação Física para a formação dos sujeitos.

\section{REFERENCIAL TEÓRICO}

\subsection{CONCEPÇÃO DE ENSINO MÉDIO INTEGRADO}

A Lei de Diretrizes e Bases da Educação Nacional (LDB) 9.394 de 1996 (BRASIL, 1996), determina o Ensino Médio como a última etapa da educação básica. Esta modalidade de ensino, é estruturada por uma diversidade de conhecimentos que se constituem em disciplinas curriculares, dentre elas, a matemática, Linguagens, Ciências, Artes, História, Geografia e Educação Física.

No Brasil, o Censo Escolar de $2019^{3}$, mostrou que o Ensino Médio propedêutico recebeu aproximadamente 7.5 milhões de matrículas em todo o país durante aquele ano. Já os anos finais do Ensino Fundamental foram quase 12 milhões de matrículas. Isso permite dizer, que trata-se de um cenário demasiadamente contraditório, pois em tese os mesmos que se matricularam na primeira etapa da educação básica, deveriam dar continuidade nos estudos.

Ou seja, 4.5 milhões de estudantes que ao concluírem o Ensino Fundamental, não ingressaram no Ensino Médio, podendo assim revelar uma das cenas de desigualdades educacionais e uma série de questões que podem e devem ser levantadas quando estudamos o Ensino Médio brasileiro.

Uma outra configuração muito próxima deste Ensino Médio propedêutico é o Ensino Médio Integrado, modalidade de curso oferta pelas redes públicas e privadas do país, regulamentada a partir do Decreto 5.154 de 2004 (BRASIL,

\footnotetext{
${ }^{3}$ CENSO ESCOLAR 2019, informações com mais detalhes verificar a página oficial do INEP em http://portal.inep.gov.br/web/guest/indicadores-educacionais. 
2004) e resolução $n^{\circ} 06$ de 20 de setembro 2012 que estabelece as Diretrizes Curriculares Nacionais para a Educação Profissional Técnica de Nível Médio (DCNEP), (BRASIL, 2012). Ramos (2008) compreende que um grande diferencial entre os dois cursos, o Ensino Médio e o EMI é que o segundo além de ser composto por conhecimentos científicos das diversas áreas do saber, é fundamentado pela perspectiva da integração entre três elementos o Trabalho, a Ciência e a Cultura.

O currículo no EMI, estrutura-se e integra-se por meio de conhecimentos materializados nas diversas disciplinas do Ensino Médio convencional e com disciplinas vinculadas aos diversos Eixos Tecnológicos existentes no Catálogo Nacional de Cursos Técnicos do Ministério da Educação. (BRASIL, 2008b).

De acordo com Ramos (2008), compreendemos o EMI sob três concepções, sendo estas, três direções específicas, mas que se convergem em sua totalidade: a integração enquanto formação humana, integração enquanto forma de se relacionar a educação básica com a educação profissional e a integração enquanto método pedagógico. Vejamos a seguir cada uma dessas compreensões.

\subsubsection{A integração enquanto formação humana}

O primeiro sentido da integração tem um caráter filosófico e diz respeito à formação humana, onde os eixos Trabalho, Ciência e Cultura são dimensões indissociáveis que explicam o caminho a ser trilhado para uma educação emancipadora dos sujeitos. Trata-se da integração de todas as dimensões da vida no processo formativo. (RAMOS, 2008, p. 3).

Para Ramos (2008), a categoria trabalho pode ser compreendida de duas maneiras. Trabalho enquanto realização humana, assim entendido como (trabalho ontológico), bem como o trabalho histórico (sentido associado ao respectivo modo de produção).

O trabalho ontológico é um conceito discutido por pensadores como Marx, Lukács e Mészáros. Para estes, antes de ser uma particularidade dos modos de produção, sejam eles, o serviçal, escravo ou capitalista, o Trabalho é um processo de interação entre o homem e a natureza. $E$ a partir da transformação da natureza que o ser humano a transforma e transforma a si mesmo. (MARX, 2013, p. 255). Em outras palavras, Ramos (2008, p. 4) concebe o Trabalho Ontológico como produção de liberdade, nesse “ [...] sentido, trabalho não é emprego, não é ação econômica específica. Trabalho é produção, criação, realização humanas. [...]" Esta ideia permite compreender a história da humanidade, "as suas lutas e conquistas mediadas pelo conhecimento humano". (RAMOS, 2008, p. 4).

Por outro lado, o Trabalho histórico materializa-se nas diversas formas de produção específica, seja o modo de produção escravocrata, servil ou o modo de produção capitalista presente nas sociedades modernas.

Para Frigotto (2012), o Trabalho incorporado pelo modo de produção capitalista, passou a referenciar o surgimento de diversas profissões e ofícios 
específicos necessários para a manutenção desse sistema. Como consequência, por tempos, a formação profissional veio preparar os sujeitos de modo a exercerem os diversos ofícios e profissões. Ao passar por um processo de formação profissional, entende-se que esse sujeito do processo formativo adquire habilidades específicas para produzir com mais eficiência e aumentar o ritmo da produção capitalista. A esse respetivo, Ramos (2008) destaca que o trabalho está intimamente relacionado aos processos formativos interessados ao modo de produção capitalista.

Já a categoria Ciência, nada mais é do que todos os conhecimentos produzidos historicamente pelo homem "[...] em processos mediados pelo trabalho". Esses conhecimentos produzidos são legitimados e se tornam válidos, porque "explicam a realidade e possibilita a intervenção sobre ela[...]" (RAMOS, 2008, p.4). Na mesma ocasião, a autora assevera que a ciência sempre esteve ligada ao processo de desenvolvimento social, desde as civilizações mais remotas, a ciência foi produzida para possibilitar formas dinâmicas de controle sobre a natureza. Não obstante, a ciência como concebida e assegurada pelas sociedades modernas, estão longe de ser uma virtude do capitalismo moderno.

Ciavatta (2012) lembra que é por meio dos conhecimentos científicos, transformados em saberes dentro do currículo escolar e organizados em forma de conteúdos de ensino, que permite-se que a compreensão e a explicação dos fenômenos naturais e sociais ocorram. Com isso desenvolve-se a tecnologia e a produção humana, "[...] possibilitando a aprendizagem significativa e a construção de novos conhecimentos [...]" (CIAVATTA, 2012, p. 94).

A outra dimensão a que Ramos (2008) discute como parte essencial na formação humana é a Cultura. Além do trabalho ser indissociável da ciência como já discutidos anteriormente, a Cultura é um elemento fundamental onde se materializa os signos e sentidos da vida humana. Logo os "[...] valores e normas que nos orientam e nos conformam como um grupo social. Grupos Sociais compartilham valores éticos, morais, simbólicos que organizam a sua ação e a produção estética e artística" (RAMOS, 2008, p. 4).

Ao analisarmos a Cultura como dimensão essencial para formação humana, citamos Soares et al. (2012) ao defenderem o conceito de Cultura Corporal de Movimento 4 (CCM), como sendo uma concepção de cultura alusiva a todos os conhecimentos de práticas corporais sistematizadas, construídos historicamente por grupos sociais. A principal razão de ser, está na execução de gestos motores em práticas como os jogos, as lutas, as danças, os esportes e a ginástica.

É nesse sentido que atribuímos no decorrer do presente texto a perspectiva para a Educação Física no EMI. A CCM como principal elemento

\footnotetext{
${ }^{4}$ Conjunto de fenômenos ou manifestações expressivas corporais em que são envolvidos os jogos, o esporte, as lutas, as danças, a ginástica e a capoeira, caracterizando a Cultura Corporal, termo utilizado por Soares et al. (2012). Para Kunz (2004), a cultura corporal e cultura intelectual compõem a Cultura Corporal de Movimento. Termos que constituem também, numa área de estudos vinculada à educação física escolar. 
de sustentação pedagógica desta disciplina escolar dentro da educação profissional dos Institutos Federais de Educação, Ciência e Tecnologia.

Esse primeiro sentido da integração enquanto formação humana, é um termo geral para compreender um tipo de educação que não é só trabalho, não é só ciência e não é só cultura. Um tipo de educação que ainda não seja exclusividade para o ensino fundamental, para o Ensino Médio ou para o ensino superior. Trata-se, então, de uma concepção de Educação Politécnica em que o Trabalho é considerado o princípio do processo de formação.

\subsubsection{A integração enquanto forma de se relacionar educação geral e educação profissional}

O segundo sentido da integração proposto por Ramos (2008), diz respeito a uma forma de se relacionar a educação básica com a educação profissional. Neste prisma, as políticas educacionais para a educação profissional no Brasil determinam a Educação Profissional Técnica de Nível Médio em três modalidades de curso, a subsequente, concomitante e a integrada, segundo as DCNEP. (BRASIL, 2012). Estas três modalidades de cursos de nível médio podem ser ofertadas tanto na rede pública quanto privada de ensino.

A modalidade subsequente diz respeito a um curso que o estudante faz após concluir o Ensino Médio, seja ele convencional propedêutico ou o próprio EMI. Todavia, a educação profissional técnica de nível médio subsequente, tem a equivalência de um curso técnico médio apenas.

O concomitante é uma modalidade de curso que ocorre paralela ao Ensino Médio com matrículas distintas, podendo ser na mesma instituição ou em instituições distintas. Em outras palavras, o estudante faz um curso técnico de nível médio ao mesmo tempo que faz o Ensino Médio.

De modo geral, há uma certa confusão quanto às diferenças entre esta modalidade e o EMI. A primeira por sua vez, trata-se de um projeto distinto do Ensino Médio, além do que, como são duas matrículas distintas, dificilmente há possibilidade de ocorrer a integração em sua dimensão ontológica, conforme discutimos anteriormente neste artigo.

Além disso, a educação profissional técnica de nível médio integrado, é a terceira categoria de curso estabelecida pelas DCNEP (BRASIL, 2012). É uma forma de curso que passou a vigorar no país a partir do Decreto 5.154 de 2004 que alterou o Decreto 2.208/1997 que proibia o Ensino Médio Integrado conforme Frigotto; Ciavatta; Ramos (2012).

Com base em Brasil (2017) foi um total de 222.893 matrículas em todos os IFs do país só no ano de 2017, período que coletamos os dados, nos cursos de EMI, sendo deste 4.014 realizadas no IFMS. Esses números mostram que o EMI é uma modalidade ainda em construção política e pedagógica quando comparada as 7.4 milhões de matrículas no Ensino Médio propedêutico, mostrado no Censo Escolar 2019 em (BRASIL 2019). 


\subsubsection{A integração enquanto currículo}

A integração também pode ser entendida nesse viés, como a relação entre parte e totalidade da proposta curricular. E esta relação se entende as diversas disciplinas que em suas particularidades do conhecimento, fundem-se em um único projeto curricular. Ramos (2012) remete que corriqueiramente o termo currículo integrado é associado ao pensamento de interdisciplinaridade. Naturalmente esta associação de que o currículo integrado pode-se ter a interdisciplinaridade como uma referência metodológica, mas que ainda não dará conta do currículo integrado.

Ramos (2012) explica que a integração enquanto parte de uma totalidade do currículo, vem se tornando uma expressão de "montar um currículo com disciplinas curriculares." Isso quer dizer que parcela das instituições de ensino que ofertam os cursos de EMI, compreende que a integração parte do pressuposto que, juntar várias áreas do conhecimento, algumas vezes em formas de disciplinas curriculares convencionais, com disciplinas dos eixos tecnológicos específicos dos cursos, estará garantindo o currículo integrado.

Lopes (2018) diz que a concepção de currículo no EMI vai além de uma composição de componentes curriculares. Trata-se de uma educação que "contemple todas as formas de conhecimentos produzidas pela atividade humana, que não separa o conhecimento científico daquele adquirido pelos educandos no cotidiano das suas relações culturais e materiais." (LOPES, 2018, p. 54). Neste viés, é um EMI em que a ciência e o trabalho, se materializam nos diversos componentes curriculares, do ensino médio propedêutico bem como das habilitações profissionais a qual o curso propõe.

\subsection{POSSIBILIDADES DA EDUCAÇÃO FÍSICA PARA O ENSINO MÉDIO INTEGRADO}

Os conhecimentos produzidos historicamente pela humanidade foram incorporados pelos currículos escolares e em sua maioria, tornaram-se conhecimentos relacionados às diversas ciências modernas, tais como a Educação Física, a Matemática, as Linguagens, as Humanidades, as Artes, dentre outras.

Estas disciplinas escolares foram categorizadas por meio da LDB 9.394/1996 e pela Base Nacional Curricular Comum do Ensino Médio (BNCC) dentro de cinco grandes áreas do conhecimento: as Linguagens e suas Tecnologias; Matemática e suas Tecnologias; Ciências da Natureza e suas Tecnologias; Ciências Humanas e Sociais aplicadas. (BRASIL, 2018). Para Darido e Rangel (2005), a unidade curricular Educação Física por sua vez, foi inserida na grande área do conhecimento Linguagem e suas Tecnologias, e a Linguagem Corporal como principal ferramenta de construção do conhecimento desta unidade curricular no Ensino Médio. 
Diante desta orientação dada pelos instrumentos legais, questionamos: quais são as possibilidades da Educação Física no EMI, a partir do entendimento e regulamentação dada pelas políticas educacionais que a considera uma linguagem? Como inserir a Educação Física no currículo do EMI tendo-a como uma linguagem corporal?

Para nos aproximarmos das possibilidades para a Educação Física Escolar no EMI, recorremos a um referencial teórico da Educação Física que há anos vem discutindo e ressignificando o seu papel bem como direcionando algumas possibilidades para a construção do seu conhecimento na escola. Neste viés, várias correntes pedagógicas surgiram a partir dos anos 1980 na perspectiva de romper com os modelos tradicionais ${ }^{5}$ que historicamente sustentaram as possibilidades da prática pedagógica da Educação Física dentro das escolas.

Para Daolio (1998), na tentativa de romper com o modelo hegemônico das aulas de Educação Física, que tradicionalmente limita-se na reprodução de gestos motores dos esportes tradicionais, foram elaboradas nos anos 1990 as primeiras documentações com um referencial crítico, fundamentado no materialismo histórico. Essas abordagens críticas passaram a questionar o caráter alienante da Educação Física na escola alegando que uma disciplina escolar que não promove a reflexão e a superação de suas práticas tecnicistas, pouco significaria para o processo de escolarização dos sujeitos.

Soares et al. (2012) defendem uma Educação Física que promova um conhecimento em seus aspectos histórico, social e político, tendo em vista a superação das desigualdades entre as classes sociais. O principal objeto de reflexão da Educação Física nessa perspectiva é denominado de Cultura Corporal e até mesmo Cultura Corporal de Movimento, que apresentam várias temáticas como o esporte, os jogos, a ginástica, as danças, lutas entre outros, os quais fazem parte do cotidiano histórico-social do aluno.

As principais abordagens críticas da Educação Física são denominadas de Tendência Pedagógica Crítico-Superadora e a Tendência Pedagógica Crítico-Emancipatória. Ambas reconhecem que para uma superação de modelos tecnicistas e tradicionais da Educação Física Escolar, deve-se considerar todos os conhecimentos históricos adquiridos pelo homem no tocante à cultura corporal de movimento como parte de uma totalidade no processo de construção do currículo da Educação Física Escolar dentro da educação profissional técnica de nível médio integrado.

A retórica da Tendência Pedagógica Crítico-Superadora ${ }^{6}$ confronta à linha mecanicista/tradicional da educação física, tendo como base o discurso da justiça social substanciado por teorias marxistas. Para a superação das práticas hegemônicas existentes até a década de 1980, Soares et al. (2012) diz que a área da educação física foi influenciada pelos educadores José Carlos

5 Como não é do nosso propósito a rediscussão dos modelos pedagógicos tradicionais da educação física, sugerimos ver os trabalhos dos autores Daolio (1998) e Soares (2004).

6 Essa tendência surgiu por volta da década de $1980 \mathrm{com}$ o propósito de denúncia da crise enfrentada pela educação física, que, até esse momento, era orientada por instituições médicas, militares e esportivas. 
Libâneo e Demerval Saviani, ambos, fundamentais na construção do pensamento crítico-superador.

Um trabalho bastante relevante que materializou essa abordagem foi publicado pela primeira vez em 1992, no livro intitulado Metodologia do ensino da Educação Física, por um coletivo de autores. Darido e Rangel (2005) dizem que esses autores acreditam que a pedagogia apropriada deve tratar, além de questões didáticas, de um determinado conteúdo, questões que valorizem o resgate dos fatores históricos, sociais, políticos dos temas que compõem a Cultura Corporal.

Esse coletivo de autores, dentre eles Valter Bracht, Celi N. Z. Taffarel, Lino Castellani Filho, Micheli Ortega Escobar, Carmen L. Soares, João P. S. Medina, entre outros, descrevem que a educação física é uma disciplina escolar cuja fundamentação teórica está vinculada a uma área denominada de Cultura Corporal. Essa, por sua vez, é caracterizada por suas atividades particularmente corporais, tais como o esporte, os jogos, as danças, a ginástica, e predispõe de conhecimentos que visam o aprendizado da expressão corporal como uma forma de comunicação ou linguagem corporal. (SOARES ET AL. 2012).

Segundo os autores, a abordagem Crítico-Superadora tem suas características específicas que visam superar as pedagogias emergentes que também propunham romper com o modelo mecânico tecnicista. Todavia, Soares et al. (2012, p. 25) reportam que "[...] explicações pedagógicas vão sendo elaboradas para lograr o consenso (convencimento) dos sujeitos, [...] cuja reflexão vincula-se à manutenção de uma hegemonia [...]". Os autores corroboram que por mais que fosse progressistas as tendências pedagógicas que vinham surgindo durante os anos de 1980 para referenciar a educação física, não tinham um caráter de superação dos modelos tradicionais. Continuam mencionando que a tendência crítico-superadora é diagnóstica, pois pretende ler os dados da realidade, interpretá-los e emitir um juízo de valor. Esse juízo é dependente da perspectiva de quem o julga. É judicativa porque julga os elementos da sociedade a partir de uma ética que representa os interesses de uma determinada classe social. Essa abordagem é também considerada teleológica, pois busca uma direção, e, dependendo da perspectiva de classe de quem reflete, "poderá ser conservadora ou transformadora dos dados da realidade diagnosticados e julgados". (SOARES ET AL. 2012, p. 25).

Para Darido e Rangel (2005), quanto à adequação dos conteúdos dentro dessa linha, são levados em consideração a sua relevância social, sua contemporaneidade e sua adequação às características sociais e cognitivas dos alunos, além de confrontar o conhecimento do senso comum do aluno, com o conhecimento científico para ampliar o seu acervo de conhecimento.

$\mathrm{Na}$ tendência crítico-superadora, a avaliação do processo de ensino aprendizagem deverá ser um momento de reflexão coletiva, que serão envolvidos vários temas, dos quais podem ser notados na seguinte citação de Darido e Rangel 
Os projetos históricos, as condutas humanas, as próprias práticas avaliativas, as decisões em conjuntos, o tempo necessário para a aprendizagem, que é o tempo pedagógico, a compreensão crítica da realidade, a ludicidade e a criatividade, os interesses, necessidades e intencionalidades objetivas e subjetivas (2005, p. 13).

Dessa maneira, a ampliação dos procedimentos didático-pedagógicos nessa abordagem ainda é pouco desenvolvida, embora haja um esforço para tanto. Com isso, outro trabalho já baseado em perspectivas diferentes aborda algumas reflexões no sentido de construir um referencial teórico-prático para o ensino da educação física no Ensino Médio e no EMI. Elenor Kunz (2004), com uma proposta de transformar pedagogicamente o esporte, aborda, em sua principal obra, intitulada Transformação didático-pedagógica do esporte, componentes de uma abordagem crítico-emancipatória estrutural para a Educação Física que muito se assemelha a crítico-superadora.

\section{METODOLOGIA}

Este trabalho teve como objetivo discutir as possibilidades do ensino da Educação Física Escolar dentro dos cursos de EMI no IFMS. Para aproximarmos deste propósito, buscamos em Marconi e Lakatos (2010) referências quanto ao tipo de pesquisa, neste caso qualitativa descritiva, com análise de documentos e pesquisa bibliográfica. Para (MARTINS, 2010) a pesquisa qualitativa permite entender os detalhes e descrever parte do objeto estudado, e assim, aproximarmos da realidade investigada.

Durante a pesquisa documental, orientamo-nos em Marconi e Lakatos (2010) e buscamos por fontes primárias, os PPCs de EMI do IFMS. Os critérios de escolha destas fontes foram estabelecidos a partir da disponibilidade pública dos documentos na página eletrônica do IFMS e por apresentarem informações compatíveis aos objetivos da pesquisa. Além destes, algumas Leis, Decretos e Diretrizes educacionais foram analisadas dentro das páginas online do Governo Federal.

Para a revisão da temática estudada e apresentação dos resultados, optamos pela pesquisa bibliográfica dos temas, Ensino Médio Integrado; Abordagens Pedagógicas na Educação Física Escolar e por fim a revisão do conceito de Cultura Corporal de Movimento. Mesmo estes conhecimentos já terem sido bastante explorados por outros estudiosos, Marconi e Lakatos (2010) dizem que a pesquisa bibliográfica permite um olhar sobre uma nova abordagem com outro enfoque, onde as considerações e conclusões podem ser inovadoras.

\section{RESULTADOS E DISCUSSÕES}


As Tendências Pedagógicas Críticas parecem ser uma boa referência didática e pedagógica à Educação Física na formação profissional técnica de nível médio integrado. Mas, devemos compreender que, pelo fato de a educação física ser uma área com múltiplas possibilidades teóricas e práticas, é oportuno salientar que a organização pedagógica desta unidade curricular no IFMS seja reflexo também da pluralidade presente na constituição histórica desta área do conhecimento.

No IFMS, ao menos dentro dos Projetos Pedagógicos de Cursos (PPCs), a educação física escolar contempla a perspectiva da Cultura Corporal de Movimento como conhecimento a ser ensinado para os estudantes que frequentam os cursos de EMI nessa instituição.

Ao analisarmos as ementas dos respectivos 36 cursos de EMI do IFMS ${ }^{7}$, percebe-se uma certa padronização do ementário, bem como uma diversidade de conteúdos distribuídos semestralmente nos currículos dos seus respectivos PPCs. Os conteúdos da Unidade Curricular Educação Física estão divididos por semestre, no decorrer dos 3 anos do curso de EMI, como no caso do curso Ensino Médio Integrado em agricultura que apresentamos na Figura 1.

Figura 1: Quadro com os principais conteúdos propostos dentro dos PPC do curso de Ensino Médio Integrado em agricultura do IFMS.

\begin{tabular}{|c|c|}
\hline $\begin{array}{l}\text { UNIDADE } \\
\text { CURRICULAR }\end{array}$ & CONTEÚDOS PRINCIPAIS \\
\hline $\begin{array}{l}\text { Educação Física } \\
1-40 \mathrm{~h} / \mathrm{a}\end{array}$ & $\begin{array}{l}\text { - Elementos históricos da educação física escolar; } \\
\text { - Conhecimentos relacionados à saúde e qualidade } \\
\text { - Ce vida; } \\
\text { - Cultura Corporal de Movimento. }\end{array}$ \\
\hline $\begin{array}{l}\text { Educação Física } \\
2 \text { - 40h/a }\end{array}$ & $\begin{array}{l}\text { - Cultura Corporal de Movimento; } \\
\text { - Conhecimentos relacionados à saúde e qualidade } \\
\text { de vida; } \\
\text { - Esportes. }\end{array}$ \\
\hline $\begin{array}{l}\text { Educação Física } \\
3-40 \mathrm{~h} / \mathrm{a}\end{array}$ & $\begin{array}{l}\text { - Conhecimentos sobre o corpo; } \\
\text { - Conhecimentos relacionados à saúde e qualidade } \\
\text { de vida; } \\
\text { - Jogos; } \\
\text { - Esportes. }\end{array}$ \\
\hline $\begin{array}{l}\text { Educação Física } \\
4 \text { - 40h/a }\end{array}$ & $\begin{array}{l}\text { - Conhecimentos sobre o corpo; } \\
\text { - } \text { Lutas; } \\
\text { - Esportes. }\end{array}$ \\
\hline Educação Física & $\begin{array}{l}\text { - Conhecimentos sobre o corpo; } \\
\text { - Esportes. } \\
\text { onte: IFMS (2017), adaptado pelo autor. }\end{array}$ \\
\hline
\end{tabular}

7 Documentos encontram-se disponíveis na página do IFMS em https://www.ifms.edu.br/cursos/integrado. 
Notamos que a denominada "Unidade Curricular Educação Física", dentro dos PPCs, prevê uma série de conteúdos pertencentes à CCM, de modo que ela mesma se torna conteúdo escolar para os estudantes (Quadro 1). Os conteúdos danças, lutas, atividades rítmicas, esportes, assuntos sobre saúde e qualidade de vida são temáticas previstas nas ementas desta Unidade Curricular.

Segundo Boscatto e Darido (2017, p. 107) os conteúdos materializam um currículo e, no caso da Educação Física Escolar para a Educação Profissional, Científica e Tecnológica. Nota-se que mesmo fazendo parte do EMI, ela ainda mantém as mesmas especificidades encontradas em estudos desenvolvidos no ensino médio regular. É o que podemos observar no (Quadro 1) quando apresentados os dados.

Podem ser avanços, dado à superação da hegemonia de estudos que até os anos 1990 eram exclusivos ao desenvolvimento do gesto desportivo. No entanto, o desafio ainda é encontrar uma Educação Física que dialogue com as perspectivas do EMI, conforme abordado no início do texto.

O que se destaca nas ementas dos PPCs, é o fato da CCM se apresentar como um conteúdo das Unidades Curriculares Educação Física 1 e 2. Enquanto que Soares et al. (2012) tratam-na como sendo uma referência conceitual para a Educação Física, não propriamente um conteúdo escolar. Por ora, vale uma breve discussão da $\mathrm{CCM}$ e a conotação que este tema tem enquanto um conteúdo para a Educação Física no Ensino Médio Integrado do IFMS.

\begin{abstract}
As formas mais básicas de movimentação podem ser combinadas de diferentes maneiras para se atender às demandas ambientais, que também são sociais e culturais. Elas podem originar outras formas de movimentação características de um período histórico, compartilhadas em uma mesma região por segmentos sociais específicos, em todo um país ou por várias nações e sociedades. $O$ conjunto desses fenômenos ou manifestações expressivas corporais tem sido denominado Cultura Corporal de Movimento, que consistiria também numa área de estudos vinculada à educação física escolar. (DARIDO; RANGEL, 2005, p. 26)
\end{abstract}

Estes fenômenos referidos por Darido e Rangel (2005), foram sistematicamente tomando-se regras, intenções e principalmente popularização entre as várias manifestações culturais na história do homem. Oliveira (2011) e Soares et al. (2012) ao defenderem um conceito para o que é a Educação Física, buscaram as relações das práticas corporais desde a construção das primeiras civilizações, até chegarem nos fundamentos metodológicos dessa área do conhecimento no ambiente escolar. Deste modo, os autores mostram que a CCM é uma possibilidade de resgatar e viver estas manifestações, seja na execução do gesto motor, como também em conceitos e atitudes correlacionadas.

Carvalho (2017) mostra que a Cultura Corporal a partir dos anos de 1980 passou a se tornar uma referência pois permitiu explicar que a Educação Física 
enquanto prática pedagógica "[...] contém objeto de conhecimento, com intenções e objetivos escolares (e por isso sua inserção na escola e sua vinculação com as ideias dessa instituição), deslocando seu foco da aptidão física". (CARVALHO, 2017, p. 254).

Conhecimentos esses vinculados ao correr, o saltar, andar, arremessar, até mesmo as mais elaboradas como as danças, lutas e jogos populares que por sinal são tão remotas quanto às primeiras civilizações. (OLIVEIRA, 2011). Nesse aspecto, o movimento ou o movimentar-se foram incorporadas pedagogicamente dentro das escolas por essa área do conhecimento e logo entendidos como conhecimentos de uma Cultura Corporal de Movimento (SOARES, ET AL. 2012).

\begin{abstract}
Na perspectiva da cultura corporal, abordando as práticas corporais como conhecimento e, chamando a atenção dos alunos sobre a tarefa ou coisa específica em curso, cada conteúdo da educação física tem diversos subsídios para realizá-lo, a partir do entendimento do que seja a prática corporal em destaque para estudos (como no exemplo das lutas, podemos iniciar por seus deslocamentos e suas gestualidades específicas (formas de atacar e defender)) - o que pode ser realizado de diversas maneiras (a execução propriamente dita, a observação de vídeos, o estudo em livros etc. (CARVALHO, 2017, p. 266).
\end{abstract}

Na prática pedagógica da Educação Física Escolar, estuda-la para além do gesto técnico como apontam Carvalho (2017) e Soares et al. (2012), implica aproximar as diversas práticas corporais e suas múltiplas relações antropológica, filosófica, histórica e biológica. $\mathrm{O}$ que pode ser um caminho para sistematizar, orientar e teorizar a Educação Física no EMI.

Se analisarmos a história do homem, diante destas relações, perceberemos que suas ações dependeram diretamente do ato físico para serem construídas. Oliveira (2011, p. 13) lembra que para construir e manter as primeiras formas de organização social, sejam elas nômades ou sedentárias, os primeiros povos dependeram diretamente da sua força física, da resistência, da velocidade, do saltar, correr e andar, visando sua própria sobrevivência. Segundo Soares (2004) e Oliveira (2011), as atividades físicas sistematizadas quase sempre estiveram ligadas às ações relacionadas à sobrevivência e que dependiam diretamente do ato físico, como, por exemplo, caçar, pescar, plantar e guerrear.

Para Soares et al. (2012 p. 39) a organização intencional das práticas corporais, a partir de movimentos corporais utilitários e guerreiros, "transformou-se num patrimônio cultural da humanidade". Os conhecimentos acumulados historicamente nestes movimentos e materializados nos elementos da CCM segundo Darido e Rangel (2005, p. 26) mereçam destaque não só pela reprodução e desenvolvimento do gesto técnico uma vez que o Lutar, o Dançar, o Jogar, 
[...] busca desenvolver uma reflexão pedagógica sobre o acervo de formas de representação do mundo que o homem tem produzido no decorrer da história, exteriorizadas pela expressão corporal: jogos, danças, lutas, exercícios ginásticos, esporte, malabarismo, contorcionismo, mímica e outros, que podem ser identificados como formas de representação simbólica de realidades vividas pelo homem, historicamente criadas e culturalmente desenvolvidas. (SOARES, ET AL. 2012, p. 39).

Ao percebermos que a CCM é uma possibilidade pedagógica no EMI do IFMS conforme mostrado no (Quadro 1), o estudante que pelo EMI passar, poderá reconhecer-se como sujeito histórico, adotar hábitos saudáveis e relacioná-los com os efeitos sobre a própria saúde e melhoria da saúde coletiva, por exemplo. Como destacam Soares et at. (2012, p. 27) a Educação Física nesta perspectiva permitirá aos estudantes uma gama de conhecimentos que criticamente serão capazes de ler e julgar os dados da realidade, propor resoluções e contudo transformar esta realidade.

\section{CONSIDERAÇÕES FINAIS}

Não esgotamos nesta pesquisa as possibilidades para a educação física escolar no EMI. Longe disso, como bem diz Marx, a ciência e o conhecimento são mutáveis e intermináveis em sua natureza. Com isso, o movimento histórico em que se insere a Educação Física Escolar, principalmente dentro do EMI, engaja-se numa constante mudança haja vista serem, a Educação Física Escolar e o Ensino Médio Integrado, fenômenos sociais, científicos e políticos.

Com esse fôlego, buscamos revisar a ideia de EMI a partir dos agentes que se debruçam sobre o assunto e se atrevem a arriscar sobre o modelo de integração no ensino médio, instituído pelos IFs. Estamos na trilha para uma educação humana integral, politécnica, democrática e este é o modelo de ensino médio defendido. Anseia-nos reconfigurar política e, pedagogicamente, a educação física escolar para tais cursos nos IFs. Por isso, mais estudos, relatar experiências, incentivar novos projetos, ouvir os sujeitos da comunidade escolar, reivindicar novas políticas educacionais são caminhos a trilhar.

Com a pesquisa, percebeu-se a construção de uma identidade pedagógica após muitos anos de crise epistemológica na EF. Afinal, sabemos que é um trabalho árduo, contudo gratificante, quando em meio aos trabalhos pedagógicos da sala de aula em mais de 13 anos, percebemos muitas são as influências para os sujeitos históricos que por nós são colocados como estudantes.

É preciso um olhar de otimismo sobre as diversas funções atribuídas ao professor, ao optarem por conteúdos como os apresentados nos dados da pesquisa, a forma como está posto o currículo e a organização institucional mostrada nos projetos pedagógicos do IFMS. Com isso arriscamos dizer que há avanços e conquistas pedagógicas para a Educação Física dentro do EMI ao notarmos a CCM como referencial. A experiência aqui apresentada reflete 
uma realidade escolar específica, e que para o Instituto Federal de Mato Grosso do Sul será fundamental para avançarem com o Projeto Pedagógico daquela instituição.

\section{REFERÊNCIAS}

BOSCATTO, J. D.; DARIDO, S. C. A educação física no ensino médio integrado à educação profissional e tecnológica: percepções curriculares. Revista Pensar a Prática, Goiânia, v. 20, n.1, jan/mar. 2017.

BRASIL. Casa Civil. Decreto n 5.154 de 23 de julho de 2004. Brasília: publicada em 23 de julho de 2004. Disponível em: http://www.planalto.gov.br/ccivil_03/_ato2004-2006/2004/decreto/d5154.htm. Acesso em: 23 fev. 2020.

BRASIL. Casa Civil. Lei no 11.892 de 29 de dezembro de 2008. Brasília: publicada em 29 de dezembro 2008. Disponível em: http://www.planalto.gov.br/ccivil_03/_Ato2007-2010/2008/Lei/L11892.htm. Acesso em: 23 fev. 2020.

BRASIL. Ministério da Educação. Portaria n 870, de 16 de julho de 2008. Catálogo Nacional de Cursos Técnicos. Brasília: Ministério da Educação, 2008b. Disponível em: http://portal.mec.gov.br/docman/novembro-2017pdf/77451-cnct-3a-edicao-pdf-1/file. Acesso em: 23 fev. 2020.

BRASIL. Ministério da Educação. Resolução nº 06 de setembro de 2012. Diretrizes Curriculares Nacionais para a Educação Profissional Técnica de Nível Médio. Brasília: Ministério da Educação, 2012. Disponível em: http://portal.mec.gov.br/index.php?option=com_docman\&view=download\&alia $\mathrm{s}=11663-$ rceb006-12-pdf\&category_slug=setembro-2012-pdf\&ltemid=30192. Acesso em: 23 fev. 2020.

BRASIL. Ministério da Educação. Lei n 4.024, de 20 de dezembro de 1961. Lei de Diretrizes e Bases da Educação Nacional. Brasília: Ministério da Educação, 1961. Disponível em:

https://www2.camara.leg.br/legin/fed/lei/1960-1969/lei-4024-20-dezembro1961-353722-normaatualizada-pl.html . Acesso em: 23 fev. 2020.

BRASIL. Ministério da Educação. Lei no 5.692, de 11 de agosto de 1971. Lei de Diretrizes e Bases da Educação Nacional. Brasília: Ministério da Educação, 1971. Disponível em:

https://presrepublica.jusbrasil.com.br/legislacao/128525/lei-de-diretrizes-ebase-de-1971-lei-5692-71 . Acesso em: 23 fev. 2020.

BRASIL. Ministério da Educação. Lei no 9.394/96, de 20 de dezembro 1996. Lei de Diretrizes e Bases da Educação Nacional. Brasília: Ministério da Educação, 1996.

BRASIL. Ministério da Educação. Plataforma Nilo Peçanha. Base de dados 2017. Brasília: Ministério da Educação, 2017. Disponível em: plataformanilopecanha.org. Acesso em: 15 de ago. 2018. 
BRASIL. Ministério da Educação. Base Nacional Curricular Comum do Ensino Médio (BNCC). Brasúlia: Ministério da Educação, 2018. Disponível em: http://basenacionalcomum.mec.gov.br/ . Acesso em: 23 fev. 2020.

BRASIL. Ministério da Educação. INEP. Censo escolar 2019. Brasília: Ministério da Educação, 2019. Disponível em:

http://portal.inep.gov.br/web/guest/indicadores-educacionais. Acesso em: 23 fev. 2020.

CARVALHO, R. M. A. A cultura corporal como concepção que organiza a educação física e caracteriza o escolar. Revista Teias, Rio de Janeiro, v. 18, n. 49, abr/jun. 2017. Disponível em: https://www.epublicacoes.uerj.br/index.php/revistateias/article/viewFile/24933/20965 . Acesso em: 16 mar. 2020.

CIAVATTA, M. A formação integrada: a escola e o trabalho como lugares de memória e de identidade. In.: FRIGOTTO, G.; CIAVATTA, M.; RAMOS, M. (Orgs.). Ensino médio integrado: concepções e contradições. 3. ed. São Paulo: Cortez, 2012.

DAOLIO, J. Educação Física Brasileira: Autores e atores da década de 1980. Campinas: Papirus, 1998.

DARIDO, S. C.; RANGEL, I. C. A. Educação Física na escola: Implicações para a prática pedagógica. Rio de Janeiro: Guanabara Koogan, 2005.

FERREIRA, E. B.; GARCIA, S. R. O. O ensino médio integrado à educação profissional: um projeto em construção nos estados do Espírito Santo e do Paraná. In.: FRIGOTTO, G.; CIAVATTA, M.; RAMOS, M. (Orgs.). Ensino médio integrado: concepções e contradições. 3. ed. São Paulo: Cortez, 2012.

FRIGOTTO, G.; CIAVATTA, M.; RAMOS, M. (Orgs.). Ensino médio integrado: concepções e contradições. 3. ed. São Paulo: Cortez, 2012.

FRIGOTTO, G. Concepções e mudanças no mundo do trabalho e o ensino médio. In.: FRIGOTTO, G.; CIAVATTA, M.; RAMOS, M. (Orgs.). Ensino médio integrado: concepções e contradições. 3. ed. São Paulo: Cortez, 2012.

IFMS. Instituto Federal de Educação Ciência e Tecnologia de Mato Grosso do Sul. Projeto Pedagógico de Curso. PPC do curso de Educação Profissional Técnica de Nível Médio Integrado em Agricultura do campus Naviraí. Naviraí MS, 2017. Disponível em: http://www.ifms.edu.br/campi/campusnavirai/cursos/integrado/agricultura. Acesso em: 27 ago. 2018.

KUNZ, E. Transformação didático-pedagógica do esporte. 6. ed. ljuí: UNIJUÍ, 2004.

LOPES, J. P. M. O componente curricular de arte/música na educação profissional: a visão do docente a respeito do currículo dos cursos técnicos integrados ao ensino médio dos institutos federais. Tese (tese doutorado em música) - Programa de Pós-Graduação em Música do Centro de Letras e Artes - UNIRIO. Rio de Janeiro, p. 54, 2018. 
MARCONI, M. A.; LAKATOS, E. M. Fundamentos de metodologia científica. 7. ed. São Paulo: Atlas, 2010.

MARTINS, J. A pesquisa qualitativa. In.: FAZENDA, I. (Org.). Metodologia da pesquisa educacional. 12. ed. São Paulo: Cortez, 2010.

MARX, K. O capital: crítica da economia política. Livro I: O processo de produção do capital. Tradução de Rubens Enderle. São Paulo: Boitempo, 2013.

OLIVEIRA, V. M. O que é Educação Física. 19. ed. São Paulo: Brasiliense, 2011.

RAMOS, M. Concepção do ensino médio integrado. In: SEED-PR.

Concepção de ensino médio integrado à educação profissional. Curitiba, 2008. Disponível em: https://tecnicadmiwj.files.wordpress.com/2008/09/ texto-concepcao-do-ensino-medio-integrado-marise-ramos1.pdf. Acesso em: 12 jun. 2018.

SOARES, C. L. Educação física no Brasil: raízes europeias e Brasil. 3. ed. Campinas: Autores associados, 2004.

SOARES, C. L. et al. Metodologia do ensino da educação física. 2. ed. São Paulo: Cortez, 2012. 